\title{
Transcranial Magnetic Simulation in the Treatment of Migraine
}

\author{
Richard B. Lipton* and Starr H. Pearlman ${ }^{\dagger}$ \\ *Departments of Neurology, Epidemiology and Population Health and the Montefiore Headache Center, Albert Einstein College of \\ Medicine, Bronx, New York 10461; and the 'Department of Biology, Armstrong Atlantic State University, Savannah, Georgia 31419
}

\begin{abstract}
Summary: Transcranial magnetic stimulation (TMS) is a diagnostic and therapeutic modality that is being developed as both an acute and preventive treatment for migraine. TMS delivers a fluctuating magnetic field from the scalp surface to induce current in the subjacent cortex. Magnetic pulses are delivered one at a time in single-pulse TMS (sTMS) or as a train of pulses in repetitive TMS (rTMS). For most of its 30-year history, TMS has been delivered in clinical and research settings using large tabletop devices. Based on the theory that sTMS may disrupt cortical spreading depression, sTMS has been studied and shown to be effective as an acute treatment for migraine with aura. Subsequent
\end{abstract}

work in animal models confirms that sTMS disrupts cortical spreading depression. To make outpatient self-treatment possible, a portable device has been developed for acute treatment of migraine with aura. Based on the theory that rTMS alters brain excitability and neurotransmitter activity, rTMS has been studied as a preventive migraine treatment. A small body of evidence suggests that rTMS may have a role, but further studies are needed. In this review, we summarize the data on TMS as a treatment of migraine, and we suggest directions for future research. Key Words: Migraine, acute treatment, cortical spreading depression, transcranial magnetic stimulation.

\section{INTRODUCTION}

Among the medical devices with potential therapeutic use in migraine, transcranial magnetic stimulation (TMS) offers substantial promise. Strong evidence suggests that single-pulse TMS (sTMS) is an effective acute treatment for migraine with aura. Emerging evidence suggests that repetitive TMS (rTMS) may have promise as a preventive treatment for migraine. In addition, TMS also has been examined as a diagnostic tool and as a treatment for an array of other neurological and psychiatric disorders. The clinical applications of TMS exploit the fact that a fluctuating magnetic field applied to the surface of the scalp noninvasively generates electrical changes in the underlying cerebral cortex.

In this review, we will first consider the history of TMS in its two major forms: 1) sTMS and 2) rTMS. After a brief review of clinical applications of TMS in other therapeutic areas, we will consider the mechanistic hypotheses that lead to the testing of TMS in migraine, distinguishing the mechanistic hypotheses for sTMS for acute treatment, and rTMS for preventive treatment.

Address correspondence and reprint requests to: Richard B. Lipton, M.D., Department of Neurology, Albert Einstein College of Medicine, 1300 Morris Park Ave, Rousso Building, Room 332, Bronx, NY 10461. E-mail: richard.lipton@einstein.yu.edu.
Next, we will review clinical studies evaluating sTMS and rTMS as migraine treatments. We close with a discussion of unanswered questions and future directions needed for a more complete understanding of the mechanisms and use of TMS in treating migraine.

\section{HISTORY AND TYPES OF TMS}

The diagnostic and therapeutic potential of TMS in neurology and psychiatry has been investigated for more than 30 years. TMS can be applied as a single pulse (sTMS), a pair of pulses, or a repeated train of pulses (rTMS). Herein, we will consider sTMS and paired pulse TMS (ppTMS) together under the rubric of sTMS.

For both sTMS and rTMS, a magnetic field is applied to the surface of the scalp. The field penetrates the scalp and induces current in the subjacent cortex. As currently used, TMS is believed to generate electrical fields in the cortex of up to $150 \mathrm{~V} / \mathrm{m}$ and to reach cortical depths between 1.5 to $3 \mathrm{~cm}$ below the skull surface. ${ }^{1}$ This induced electric field alters the membrane potentials of specific neuronal populations, ultimately resulting in either a depolarization or hyperpolarization of exposed cells. These electrical changes in the brain are believed to give rise to the measurable neurochemical sequella as measured by modifications in brain neurotransmitters, which are reviewed briefly herein. 
Applications of sTMS have included activation of motor cortex to measure motor conduction times, assessment of cortical excitability, and the acute treatment of migraine, as well as tinnitus. ${ }^{1}$ Paired pulse TMS can be used to deliver a double pulse to either one or two distinct cortical areas. Administration to the occipital cortex elicits a phosphene response in the contralateral visual hemifield. TMS has been used to measure phosphene threshold in persons with migraine as an index of brain excitability. ${ }^{2}$ These studies support the presence of cortical hyperexcitability in persons with migraine with aura.

Repetitive TMS (rTMS) delivers a repeated series of magnetic impulses to the cortex. rTMS is further categorized based on the frequency of the impulse sequences as either high-frequency rTMS (also called fast; frequency $>1 \mathrm{~Hz}$ ) or low-frequency (also called slow; frequency $\leq 1 \mathrm{~Hz}$ ). Most commonly, rTMS is delivered as short bursts at a high frequency (with intermittent pauses when stimulation temporarily stops). In studies of rTMS, stimulation parameters vary in frequency, intensity, train duration, and inter-train interval times. Variation in stimulus parameters among studies makes crossstudy comparisons difficult. ${ }^{1}$ The relationship between stimulus parameters and clinical outcome has generally not been well explored. The pattern, frequency, and intervals for rTMS application that might be optimal for investigative purposes or clinical treatment of selected conditions, such as tinnitus, schizophrenia, or migraine require further study.

For most of its history, both sTMS and rTMS have been delivered using large, tabletop devices. Patients come to medical settings and receive treatment from trained medical personnel. For acute migraine therapy, which requires patients to make a clinic visit, the travel to the clinic is a barrier to use, because it will delay treatment, leaving patients in pain and perhaps diminishing therapeutic effectiveness. To address these issues, light weight, portable TMS devices have been developed for acute self-treatment of migraine outside the clinic. Portable devices are appropriate for sTMS or ppTMS, but are not capable of delivering rTMS to date.

\section{CLINICAL APPLICATIONS OF TMS}

TMS has been studied as a treatment for an array of psychiatric and neurologic disorders. Psychiatric disorders include depression, ${ }^{3-6}$ acute mania, ${ }^{7,8}$ bipolar disease, ${ }^{9-11}$ panic disorder, ${ }^{11}$ schizophrenia, ${ }^{12,13}$ post-traumatic stress disorder, ${ }^{14}$ and substance abuse, ${ }^{15}$ among others. Neurologic disorders include Parkinson's disease, ${ }^{16-18}$ dystonia, ${ }^{19}$ tinnitus, ${ }^{20}$ epilepsy, ${ }^{21,22}$ and stroke, ${ }^{23}$ as well as a variety of pain syndromes including neuropathic pain ${ }^{24}$ and migraine. ${ }^{25,26} \mathrm{We}$ will first consider therapeutic applications of sTMS and then rTMS.

\section{sTMS}

sTMS has been evaluated in conditions without gross changes in brain structure. These include tinnitus and migraine, among others. ${ }^{26,27}$ In the absence of external auditory cause, some patients experience chronic tinnitus, a condition often attributed to a hyperexcitable auditory cortex. Langguth et $\mathrm{al}^{26}$ evaluated the relationship between tinnitus and changes in cortical excitability after TMS. In a small crossover study, single and paired-pulse TMS resulted in intracortical inhibition, intracortical facilitation, and prolongation of the cortical silent period. These physiologic changes were associated with improvement in tinnitus scores. Similarly, in patients with migraine, the presence of aura is the clinical manifestation of cortical spreading depression, a clear indicator of abnormal cortical function.

\section{rTMS}

rTMS has been studied in a broader range of neurologic and psychiatric disorders. Herein, we will highlight the studies in depression and Parkinson's disease to provide a context for the research on migraine. Multiple randomized clinical trials have been done establishing the clinical efficacy of rTMS for the treatment of medication-resistant depression, and regulatory approval for this indication is now available in several countries, including the United States, Israel, and Canada. Reviewing the data on the clinical application of TMS in depression, there are several studies supporting clinical benefits for reducing clinical depression scores, and in some cases remission was achieved. ${ }^{6,7}$ Large-scale reviews and multiple meta-analyses reach the consensus that rTMS is effective in some patients for the treatment of drugresistant depression. ${ }^{28,29}$

Parkinson's disease is one of the neurodegenerative diseases in which sTMS has been studied. Results have been encouraging in some studies and discouraging in others. ${ }^{17,18}$ This variability may arise (at least in part) due to differences in treatment protocols and differences in the severity of illness at the time of treatment. In patients with advanced neural degeneration, the substrate required for effective treatment may be lost.

\section{Proposed mechanisms of TMS as a migraine treatment}

In this section we will first provide a brief overview of the mechanisms of migraine and then link that to the biological models for the mechanisms of sTMS and then rTMS.

\section{Comments on the mechanisms of migraine}

Migraine is a chronic disorder with episodic attacks. ${ }^{30}$ Between attacks there is a state of sustained state of brain hyper-excitability that has a strong inherited basis. ${ }^{31,32}$ Evidence for brain hyperexcitability in migraine comes from several sources. Neurophysiologic studies in hu- 
mans with migraine show an increased amplitude of visual evoked potentials ${ }^{33,34}$ and absence of habituation. $^{35-38}$ Several well-characterized genetic causes of migraine are characterized by elevations in synaptic glutamate, the major excitatory neurotransmitter in the mammalian brain. ${ }^{39,40}$ In addition, Cao et al $^{41}$ suggest that the visual cortex in migraineurs is hyper-excitable, whereas others report reduced pre-activation excitability in the visual cortex of migraineurs. ${ }^{42}$ Studies using TMS report a reduction in the phosphene threshold in persons with migraine; treatment with migraine preventive medications raises the phosphene threshold. ${ }^{2}$ Preventive medications are believed to modulate that state of brain excitability, making it more difficult to initiate attacks. ${ }^{43}$ During the migraine aura, a wave of excitation followed by a wave of inhibition marches over the cortical mantle. These events provide direct evidence of neural hyperexcitability in migraine.

\section{Mechanisms of sTMS as an acute treatment for migraine}

The aura of migraine is believed to have cortical spreading depression (CSD) as its physiologic substrate. In its most common form, CSD occurs in the occipital cortex, giving rise to visual aura. Neuroimaging studies support the view that migraine aura is attributable to CSD. ${ }^{44-46}$ In animal models, a pinprick to the cortex elicits CSD as a wave of neuronal activity similar to the phenomenon observed in humans during aura. Recent evidence suggests that CSD gives rise to pain by activating trigeminal nociceptors in the meninges. ${ }^{47,48}$

Dr Robert Fischell originally hypothesized that sTMS may be an effective acute treatment for migraine if the cortical current it generates disrupts CSD (personal communication), which subsequently led to further studies of sTMS in migraine. Empirical evidence for this hypothesis emerged from the demonstration that sTMS inhibited CSD in animal model in comparison with sham treatment. ${ }^{49} \mathrm{Col}-$ lectively, these studies suggest that sTMS may be an effective acute treatment for patients with migraine with aura. The role of sTMS in migraine without aura is discussed in the final section of this article.

\section{Mechanism of rTMS as a preventive treatment for migraine}

If sTMS acutely treats migraine by disrupting CSD, perhaps rTMS may be helpful in preventing migraine by producing sustained changes in brain excitability and by modulating neurotransmitter levels. Several studies report specific neurotransmitter changes after rTMS. For example, after frontal lobe stimulation with $20 \mathrm{~Hz}$ there was a marked increase in dopamine in the hippocampus. ${ }^{50}$ rTMS on the left dorsolateral prefrontal cortex was followed with a reduction in $\left[{ }^{11} \mathrm{C}\right]$ raclopride binding in the caudate nucleus, suggesting changes in dopamine transmission. ${ }^{51}$ The changes in glutamate/glutamine lev- els have also been reported after rTMS to the dorsolateral prefrontal cortex. ${ }^{52}$

It is not clear how these neurochemical changes translate into therapeutic effects. For Parkinson's disease, rTMS may elevate synaptic dopamine, a mechanism similar to the pharmacologic therapies, which also aims to elevate dopamine levels in these patients. TMS may produce long-term changes in neuronal excitability or synaptic changes that resembles long-term potentiation; other potential changes may include neuronal excitability after exposure or activation of secondary pathways and feedback loops. ${ }^{1}$

Recent studies suggest that high frequency rTMS conditioning normalizes excitability in migraine patients, which may open opportunities for use of rTMS for migraine prevention. ${ }^{53}$

\section{TMS in the treatment of migraine}

Migraine is a disabling illness that presents with episodic attacks of pain, nausea, vomiting, photophobia, and phonophobia. Pharmacologic treatment approaches are divided into acute and preventive strategies. Acute treatment is given at the time of an attack to relieve pain and restore function. Preventive treatment is given on a daily basis, whether or not pain is present, to reduce the frequency or severity of attacks. sTMS has been tested as an acute treatment for migraine with and without aura. rTMS has been tested as a preventive treatment. We will consider these approaches one at a time.

\section{sTMS as an acute migraine treatment}

Efficacy of sTMS as an acute treatment has been reported in several studies (Table 1). The first was a small pilot study that randomized 42 subjects with migraine (including five subjects with aura) to either high intensity or low intensity double-pulse sTMS. ${ }^{26}$ Eligible patients were instructed to go to the clinic with the onset of their migraine. sTMS treatment was administered at the clinic using a tabletop device. Migraine headache pain was monitored at 5-minute intervals after treatment for 20 minutes or less. Treatment with TMS was associated with a $75 \%$ decrease in pain intensity scores from baseline measures. Of those who received one treatment $(\mathrm{n}=$ 42; with a maximum of three applications permitted), $32 \%$ reported no further headache at $24 \mathrm{~h}$. Recurrence of headache was reduced by $48 \%$ after a single application of sTMS stimulation. One of the interesting findings in Clarke et al's ${ }^{27}$ studies was that for patients with aura $(n=5)$, all of them achieved pain relief with sTMS treatment.

Based on the results of this study, Mohammad et al. ${ }^{54}$ focused on patients who had migraine with aura. Subjects who experienced migraine with $75 \%$ or more of their attacks were eligible for participation in this double-blind, randomized, parallel group, placebo-controlled study. At the onset of migraine pain, patients reported to 
Table 1. Efficacy of sTMS for Acute Migraine Treatment

\begin{tabular}{|c|c|c|c|c|c|}
\hline sTMS_Acute Tx & Study Design & $\begin{array}{l}\text { Number of } \\
\text { Patients }\end{array}$ & $\begin{array}{l}\text { Device/Site of } \\
\text { Application }\end{array}$ & $\begin{array}{l}\text { Dose and } \\
\text { Frequency }\end{array}$ & $\begin{array}{l}\text { Response/Primary } \\
\text { Endpoint }\end{array}$ \\
\hline $\begin{array}{l}\text { Lipton et al., } \\
2010 \\
\text { Migraine with aura } \\
30 \% \text { of attacks; } \\
<8 \text { attacks/mo }\end{array}$ & $\begin{array}{l}\text { Randomized, sham- } \\
\text { controlled, double } \\
\text { blind }\end{array}$ & $\mathrm{n}=201$ & $\begin{array}{l}\text { Portable } \\
\text { sTMS over } \\
\text { occiput }\end{array}$ & $\begin{array}{l}2 \text { pulses; } 30 \mathrm{~s} \\
\text { interval }\end{array}$ & $\begin{array}{l}2 \mathrm{H} \text { pain-free response } \\
\text { rates: TMS }=39 \% \\
\text { sham }=22 \% ; p= \\
0.0179\end{array}$ \\
\hline $\begin{array}{l}\text { Clarke et al., } \\
2006 \\
\text { Episodic migraine }\end{array}$ & $\begin{array}{l}\text { Randomized to high- } \\
\text { or low-impulse } \\
\text { group }\end{array}$ & $\mathrm{n}=42$ & $\begin{array}{l}\text { Tabletop clinic- } \\
\text { based } \\
\text { sTMS over area of } \\
\text { brain generating } \\
\text { pain or aura }\end{array}$ & $\begin{array}{l}2 \text { pulses, } 5 \mathrm{~s} \\
\text { interval }\end{array}$ & $\begin{array}{l}69 \% \text { reported } \\
\text { improvement; } 32 \% \\
\text { reported pain-free at } \\
24 \mathrm{~h} \text {. }\end{array}$ \\
\hline $\begin{array}{l}\text { Mohammad et } \\
\text { al., } 552006 \\
\text { Migraine with aura } \\
75 \% \text { of the time; } \\
<7 \text { attacks } / \text { mo }\end{array}$ & $\begin{array}{l}\text { Randomized, double } \\
\text { blind, parallel } \\
\text { group, } \\
\text { sham-controlled }\end{array}$ & $\begin{array}{l}n=42 \\
\quad(50 \text { attacks })\end{array}$ & $\begin{array}{l}\text { Tabletop } \\
\text { Clinic-based } \\
\text { sTMS over } \\
\text { occiput }\end{array}$ & 2 pulses, $30 \mathrm{~s}$ & $\begin{array}{l}69 \% \text { reported mild pain or } \\
\text { no pain at } 2 \text {-h versus } \\
48 \% \text { sham }(p=0.1)\end{array}$ \\
\hline $\begin{array}{l}\text { Mohammad et } \\
\text { al., } 542006 \\
\text { Migraine with aura } \\
75 \% \text { of the time; } \\
2-4 \text { attacks/mo }\end{array}$ & Open label, 3-month & $\mathrm{n}=12$ & $\begin{array}{l}\text { Portable sTMS; } \\
\text { over occiput }\end{array}$ & $\begin{array}{l}2 \text { pulses, } \\
\text { onset of } \\
\text { aura }\end{array}$ & $\begin{array}{l}81 \% \text { of attacks pain-free at } \\
2 \mathrm{~h} \text { after treatment }\end{array}$ \\
\hline
\end{tabular}

sTMS = single-pulse transcranial magnetic stimulations; TMS = transcranial magnetic stimulation; Tx $=$ treatment.

the hospital where they were treated with a tabletop device using two sTMS applications administered $30 \mathrm{~s}$ apart. Two hours after treatment, $69 \%$ of the TMS treatment group reported no or mild pain versus $48 \%$ of sham-treated controls $(p=0.10)$. The study also examined associated symptoms. Two hours post-treatment the percent of subjects treated with sTMS versus sham stimulation was as follows: no phonophobia ( $84 \%$ vs $17 \%$; $p=0.0002$ ), no photophobia ( $64 \%$ vs $22 ; p=0.0064)$, and no nausea ( $88 \%$ vs $56 \% ; p=0.10$ ). The study by Mohammad et al. ${ }^{54}$ was viewed as promising, but it had several limitations. In general, acute migraine treatment is taken as soon as possible after an attack to minimize pain and optimize the benefits of treatment. Conventional TMS equipment is designed to be used by medical personnel in an inpatient or outpatient treatment setting. Traveling to a treatment center is a major impediment to widespread adoption of TMS and self-treatment at home is preferred. To facilitate home treatment, a handheld, lightweight, sTMS device was developed (by a commercial entity [Neuralieve, Sunnydale, CA]) for home use (FIG. 1).

A small pilot study using the handheld device was conducted to assess efficacy in migraine with aura. ${ }^{55}$ This was an open-label, 3 -month study in adults $(\mathrm{n}=12)$ who treated 31 attacks. After two single-pulse TMS stimulations, $81 \%$ of attacks were pain-free 2 hours after treatment. TMS treatment was also associated with no nausea, no photophobia, and no phonophobia. To facilitate blinding, a sham stimulation device was developed that vibrated and clicked. Pilot testing showed that volunteers could not distinguish genuine from sham sTMS.

The positive results with the handheld device were followed by a phase III, multi-centered, sham-controlled trial to assess the efficacy and safety of sTMS in the acute treatment of migraine with aura. ${ }^{25}$ Subjects with migraine $(n=201)$ were eligible based on a history of experiencing aura with at least $30 \%$ of their migraine attacks. When aura occurred it had to be followed by the development of moderate or severe headache in more than $90 \%$ of attacks. The study was conducted in 22 centers. Patients were instructed to treat as soon as possible after the aura had begun. They were asked to apply

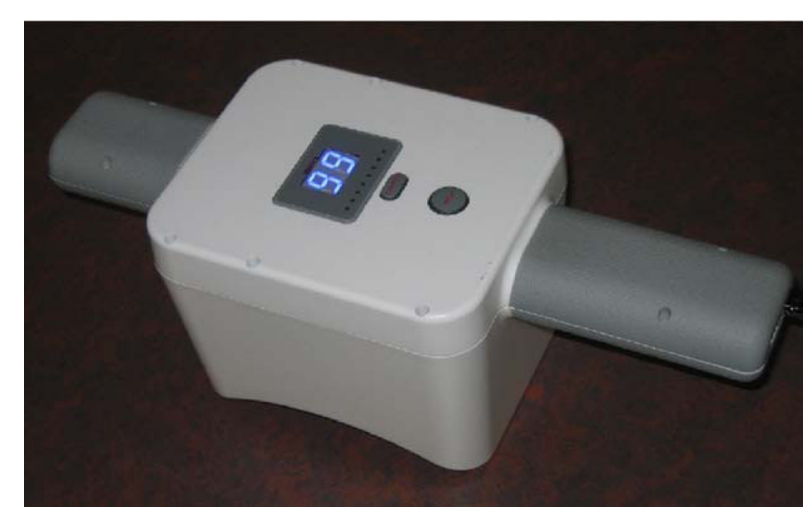

FIG. 1. Photograph of portable single-pulse transcranial magnetic stimulations (sTMS) device that allows patients to self treat for the acute treatment of migraine. The device is $32 \mathrm{~cm}$ long (13 inches) and weighs $1.54 \mathrm{~kg}$ (3.4 lbs). Manufactured by Cerena Transcranial Magnetic Stimulator; Neuralieve. 


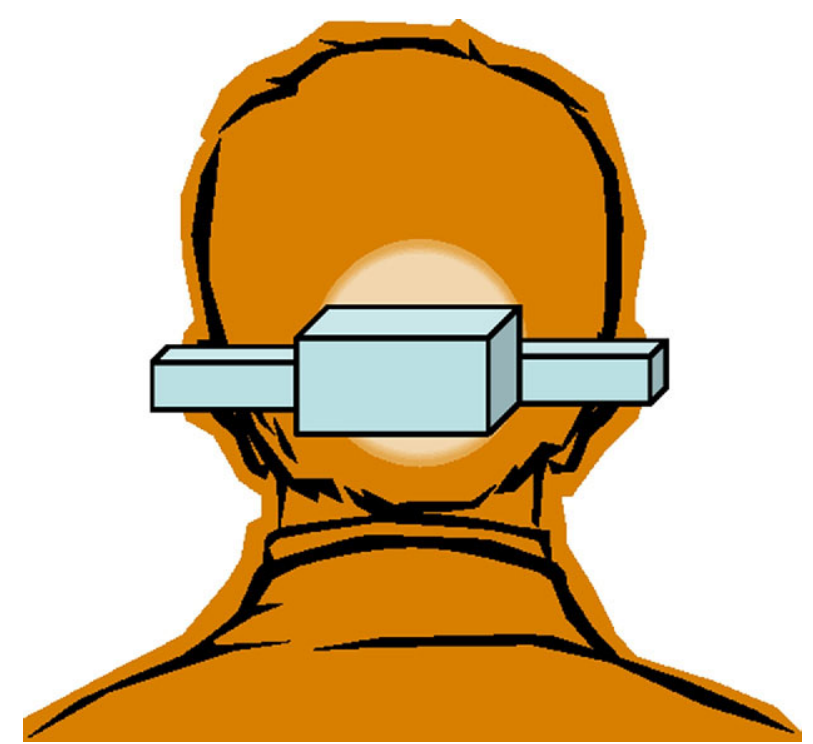

FIG. 2. Illustration of position of single-pulse transcranial magnetic stimulations (sTMS) device on the occiput. Placement of sTMS portable device on occiput during the acute treatment of migraine.

the portable sTMS device to the occiput and deliver two sTMS impulses 30 seconds apart (FIG. 2). The primary efficacy endpoint was the 2-h pain-free response. Pain-free rates were significantly higher with sTMS treatment (39\%) than with sham stimulation (22\%; $p=0.018$; FIG. 3). To ensure that TMS treatment also caused no exacerbation of migraine symptoms, the study was designed to find noninferiority for relief of nausea, photophobia, and phonophobia. The study met all of its noninferiority endpoints, demonstrating that treatment did not make symptoms worse. sTMS was also shown to reduce pain in subjects who had migraine headache of moderate severity at the time of TMS treatment (FIG. 4). The most common adverse events reported in the TMS group were headache, migraine, and sinusitis.

\section{rTMS as a preventive treatment}

The efficacy of rTMS has been tested for migraine prevention (Table 2). In a small pilot study, Brighina et al. ${ }^{56}$ assessed whether high-frequency rTMS in comparison with left dorsilateral prefrontal cortex could relieve chronic migraine. Patients were randomly assigned to 12 sessions of active $(n=6)$ or sham $(n=5)$ treatment. Subjects treated by high-frequency rTMS showed a significant reduction of the outcome measures during and in the month after the treatment as compared with 1-month baseline measures. No significant differences in the outcome measures were observed in the placebo group.

Teepker et al. ${ }^{57}$ assessed the efficacy of low-frequency rTMS in migraine prevention. Twenty-seven migraineurs were treated with rTMS for 5 consecutive days. Two trains of 500 pulses with a frequency of $1 \mathrm{~Hz}$ were applied over the vertex, which was associated with a decreased frequency of migraine attacks, migraine days, and migraine hours when compared with before the rTMS treatment, although no differences were observed between treatments. Headache frequency declined in the rTMS group, but not in the sham group relative to base-

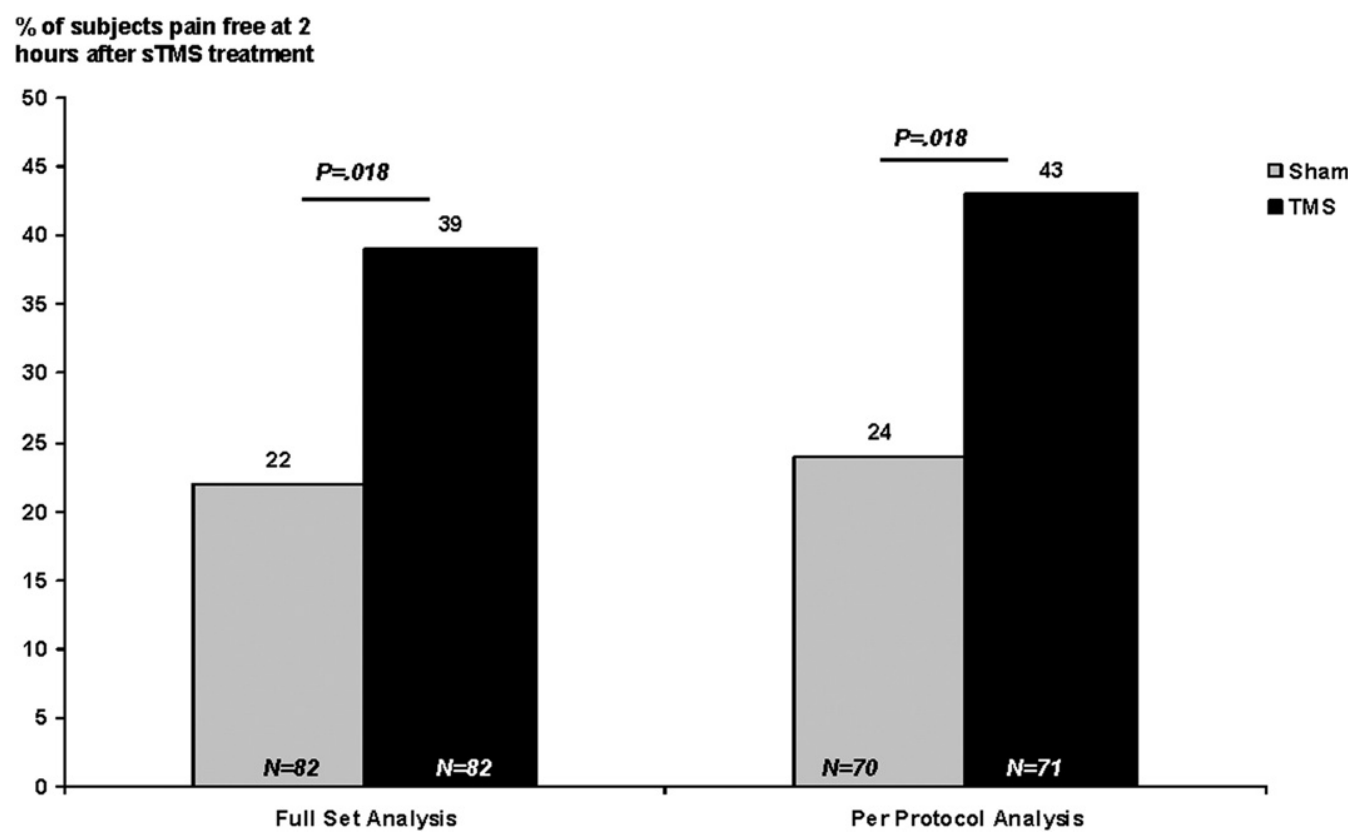

FIG. 3. Pain-free rates at $2 \mathrm{~h}$ post-treatment. Subjects were randomized to receive a single migraine attack using either two pulses of single-pulse transcranial magnetic stimulations (sTMS) or sham (summarized elsewhere, see Lipton et al. ${ }^{25}$ ). Treatment was associated with significantly lower 2-h pain-free responses for both the full set analysis patients and the intent-to-treat analysis compared to controls. $^{25}$ Improvement in the percent of subjects who achieved a pain-free status was maintained at 24 and $48 \mathrm{~h}$ post-treatment as compared to sham-treated controls. ${ }^{25}$ TMS $=$ transcranial magnetic stimulations. 


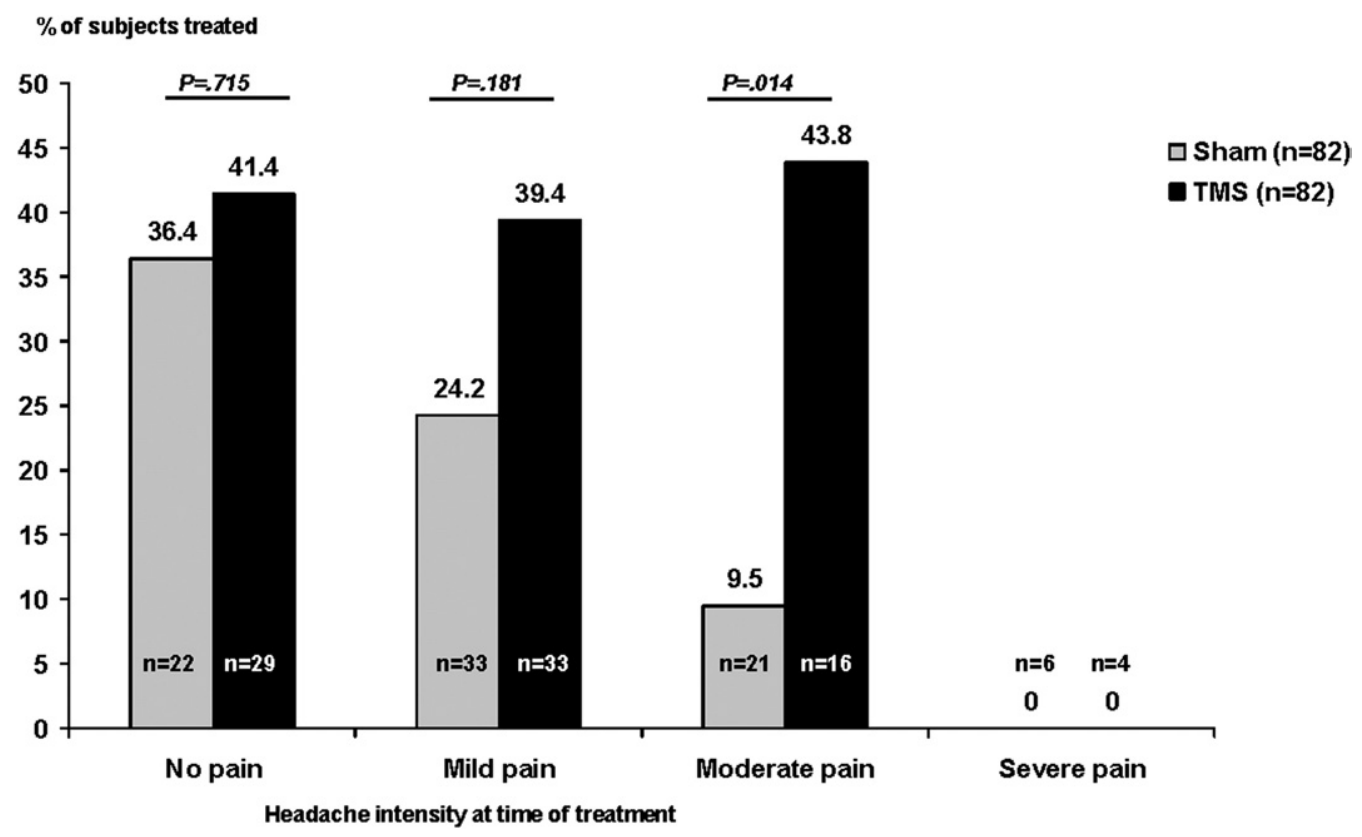

FIG. 4. Response to single-pulse transcranial magnetic stimulations (sTMS) determined on baseline pain. Assessment of baseline pain at time of treatment may influence response to therapy. In this study by Lipton et al., ${ }^{25}$ baseline pain measures were used to assess efficacy of sTMS for treating different pain intensities associated with a migraine attack. Treatment of moderate migraine pain using sTMS was associated with a significant reduction in pain compared to sham-treated controls. TMS = transcranial magnetic stimulations.

line; however, no differences were observed between sham and active treatments.

\section{TMS SAFETY}

The safety of TMS has been recently reviewed. ${ }^{58} \mathrm{Al}-$ though the studies are limited in persons with migraine, years of clinical use and extensive patient exposure allows assessment of TMS safety in patients. Single exposures of TMS are not associated with any significant magnetic field risks because the exposure is very brief. In 82 subjects treated with sTMS for the acute treatment of migraine with aura, the most common side effects included headache $(2 \%)$, migraine $(2 \%)$, and sinusitis
$(2 \%) .{ }^{25}$ Although the seizure has been reported as a risk associated with rTMS, the incidence of seizure associated with sTMS is rare.

Seizure is the most common adverse event associated with rTMS, although the overall risk is very low. The earlier studies using higher intensity or more frequent applications were associated with reports of seizures. Studies have shown that seizures may be experimentally induced with rTMS when pulses are applied with a relatively high frequency and with short periods of time between trains of stimulation. With some TMS devices, a loud clicking sound is noted; this has the potential to cause mild hearing loss. Hearing may be protected with

Table 2. Efficacy of rTMS for Migraine Prevention

\begin{tabular}{|c|c|c|c|c|c|}
\hline $\begin{array}{l}\text { rTMS- } \\
\text { Preventive Tx }\end{array}$ & Study Design & $\begin{array}{l}\text { Number of } \\
\text { Patients }\end{array}$ & $\begin{array}{l}\text { Device/Site of } \\
\text { Application }\end{array}$ & $\begin{array}{l}\text { Dose and } \\
\text { Frequency }\end{array}$ & Response/Primary Endpoint \\
\hline $\begin{array}{l}\text { Teepker et al., }{ }^{57} \\
2009 \\
\text { Migraine }>4 \\
\text { attacks per } \\
\text { month }\end{array}$ & Pre-post design & $\mathrm{n}=27$ & Tabletop & $\begin{array}{l}500 \text { pulses; } \\
1 \mathrm{~Hz} \text { for } 5 \text { days }\end{array}$ & $\begin{array}{l}27.5 \% \text { reduction in number } \\
\text { of migraine attacks } \\
\text { versus baseline } \\
(p=0.007 ; \text { NS vs sham } \\
p=0.216)\end{array}$ \\
\hline $\begin{array}{l}\text { Brighina et al., } \\
2004 \\
\text { Chronic } \\
\text { migraine }\end{array}$ & $\begin{array}{l}\text { Randomized, double-blind, } \\
\text { sham control }\end{array}$ & $\mathrm{n}=11$ & $\begin{array}{l}\text { Tabletop/ } \\
\text { dorsolateral } \\
\text { prefrontal } \\
\text { cortex }\end{array}$ & $\begin{array}{l}10 \text { trains or } 2 \mathrm{~s} \\
\text { duration; } \\
30 \mathrm{~s} \\
\text { intervals; } \\
12 \text { sessions on } \\
\text { alternate } \\
\text { days }\end{array}$ & $\begin{array}{l}\text { Improvement over baseline } \\
\text { in attack frequency, } \\
\text { acute treatment use, } \\
\text { headache index; } \\
\text { NS versus sham }\end{array}$ \\
\hline
\end{tabular}

$\mathrm{rTMS}=$ repetitive transcranial magnetic stimulations; $\mathrm{NS}=$ not significant; $\mathrm{Tx}=$ treatment. 
ear plugs. Roth et al. ${ }^{58}$ have also reported electrode heating or burns when rTMS is administered in patients also wearing EEG electrodes. Loo et al. ${ }^{28}$ report the results of a large meta-analysis assessing the safety of TMS for depression. Pain or discomfort (including scalp discomfort) was the most common adverse event associated with rTMS and was reported in $39 \%$ compared to $15 \%$ of controls (sham). Headache was reported in $28 \%$ of subjects receiving rTMS compared to $16 \%$ of controls. Pain or discomfort reported is caused when rTMS produces a twitch in the scalp, which for some is reported as uncomfortable or painful.

Importantly, in the clinical studies of depression, rTMS was applied to the forehead and frontal cortex region, an area finely innervated by the trigeminal nerve. For application of TMS to the parietal or occiput regions, cutaneous sensitivity may be reduced and the incidence of adverse events may be lower. An increase in onset of migraine after rTMS was not found. ${ }^{56}$

The magnetic field generated by TMS may interact with some selected metals, including some cranial implants. TMS should be avoided in patients with these ferromagnetic implants or in patients with pacemakers, implantable cardioverter defibrillators, and/or vagal nerve stimulators. Some titanium implants are not reactive and may prove safe for TMS exposure. Use of TMS in patients with aneurysm clips, cochlear implants, or other reactive devices should be considered on an individual basis. Removal of glasses, watches, jewelry, and other magnetically reactive accessories is also advised.

One of the primary concerns with TMS application is brain tissue heating with increased heating more associated with repeated exposure or high intensity and frequency exposure than single- or low-frequency applications. Therefore, safety profiles of sTMS and rTMS should be considered separately. Tissue heating associated with single pulse is small and estimated to be less than $0.1^{\circ} \mathrm{C} .^{59}$ In comparison to other treatments, deep brain stimulation electrodes are estimated to generate a maximum of $0.8^{\circ} \mathrm{C}$ change in exposed tissue temperature. $^{60}$

\section{CONCLUSIONS}

TMS has a long track record of safety in a broad range of applications, both diagnostic and therapeutic. Years of research, investigational applications, and clinical use has provided extensive patient exposure demonstrating high levels of both safety and tolerability. These studies show that rTMS and sTMS administration are safe for the treatment of a variety of neurological and psychiatric disorders. However, given the excitability of the cortex in patients with epilepsy or possibly the lack of inhibitory mechanisms, the safety and tolerability in persons with epilepsy remains to be understood, particularly for rTMS. Rossi et $\mathrm{al}^{1}$ report sTMS is rarely associated with an increased risk of inducing seizures, low frequency rTMS rarely induces seizure (and usually exerts a protective effect), and high frequency rTMS is associated with a possible $1.4 \%$ crude risk estimate in patients with epilepsy.

Emerging evidence suggests that sTMS is effective in the acute treatment of migraine with aura. Efficacy in the acute treatment of migraine without aura remains to be rigorously studied. rTMS has promise in the preventive treatments for migraine. For acute treatment, the portable device will provide opportunities for self-treatment with sTMS shortly after the onset of aura, without having to go to a clinic for treatment. Given that migraine attacks are often unpredictable, easy administration of treatment will be a benefit.

Additional studies are still needed to further assess the efficacy of sTMS in migraine without aura. If sTMS works by disrupting CSD, the mechanism in migraine without aura may not be obvious. However, it has been suggested that CSD in ineloquent cortex may give rise to the premonitory phase of migraine. ${ }^{31}$ Thus, sTMS should be studied in patients without aura who do and do not have a premonitory phase.

In addition, the optimal timing for sTMS in relation to both the aura and the onset of headache remains to be determined. The optimal number of pulses and optimal stimulus parameters for those pulses are also uncertain. Variations in field strength, as well as the precise site and number of applications, may influence therapeutic responses. The role of sTMS when used in combination with preventive or acute pharmacotherapy also merits further study. In the pivotal study of sTMS in migraine with aura, use of preventive treatment was a significant predictor of a favorable response. ${ }^{25}$ The absolute risk reduction was much greater in those using preventive treatments (32.1\% vs $8.3 \%$ for no preventive treatments).

For rTMS, adequately blinded and powered studies for migraine prevention would be appropriate. The role of aura and cortical spreading depression remain to be determined as if these patients are more or less likely to respond to treatment. With the development of portable sTMS devices, additional studies will allow further exploration to optimizing treatment in migraine with or without aura.

\section{REFERENCES}

1. Rossi S, Hallett M, Rossini PM, Pascual-Leone A, and the Safety of TMS Consensus Group. Safety, ethical considerations, and application guidelines for the use of transcranial magnetic stimulation in clinical practice and research. Clin Neurophysiol 2009;120: 2008-2039.

2. Aurora SK, Welch KM, Al-Sayed F. The threshold for phosphenes is lower in migraine. Cephalalgia 2003;23:258-263. 
3. Couturier JL. Efficacy of rapid-rate repetitive transcranial magnetic stimulation the treatment of depression: a symptomatic review and meta-analysis. J Psychiat Neurosci 2005;30:83-90.

4. Gershon AA, Dannon PN, Grunhaus L. Transcranial magnetic stimulation in the treatment of depression. Am J Psychiat 2003; 160:835-845.

5. Avery DH, Holtzheimer PE 3rd, Fawaz W, et al. A controlled study of repetitive transcranial magnetic stimulation in medicationresistant major depression. Biol Psychiatry 2006;59:187-194.

6. Pascual-Leone A, Rubio B, Pallardó F, Catalá MD. Rapid-rate transcranial magnetic stimulation of left dorsolateral prefrontal cortex in drug-resistant depression. Lancet 1996;348:233-237.

7. Praharaj SK, Ram D, Arora M. Efficacy of high frequency (rapid) suprathreshold repetitive transcranial magnetic stimulation of right prefrontal cortex in bipolar mania: a randomized sham controlled study. J Affect Disord 2009;117:146-150.

8. Kaptsan A, Yaroslavsky Y, Applebaum J, Belmaker RH, Grisaru N. Right prefrontal TMS versus sham treatment of mania: a controlled study. Bipolar Disord 2003;5:36-39.

9. Nahas Z, Kozel FA, Li X, Anderson B, George MS. Left prefrontal transcranial magnetic stimulation (TMS) treatment of depression in bipolar affective disorder: a pilot study of acute safety and efficacy. Bipolar Disord 2003;5:40-47.

10. Fregni F, Simon DK, Wu A, Pascual-Leone A. Non-invasive brain stimulation in neurology-perspectives on the therapeutic potential of rTMS and tDCS. Nat Clin Pract Neurol 2007;3:383-393.

11. Prasko J, Záleský R, Bares M, et al. The effect of repetitive transcranial magnetic stimulation (rTMS) add on serotonin reuptake inhibitors in patients with panic disorder: a randomized, double blind sham controlled study. Neuro Endocrinol Lett 2007; 28:33-38.

12. Matheson SL, Green MJ, Loo C, Carr VJ. Quality assessment and comparison of evidence for electroconvulsive therapy and repetitive transcranial magnetic stimulation for schizophrenia: a systematic meta-review. Schizophr Res 2010 Jan 29; [Epub ahead of print].

13. Hoffman RE, Gueorguieva R, Hawkins KA, et al. Temporoparietal transcranial magnetic stimulation for auditory hallucinations: safety, efficacy and moderators in a fifty patient sample. Biol Psychiatry 2005;58:97-104.

14. Cohen H, Kaplan Z, Kotler M, Kouperman I, Moisa R, Grisaru N. Repetitive transcranial magnetic stimulation of the right dorsolateral prefrontal cortex in posttraumatic stress disorder: a doubleblind, placebo-controlled study. Am J Psychiatry 2004;161:515524.

15. Camprodon JA, Martínez-Raga J, Alonso-Alonso M, Shih MC, Pascual-Leone A. One session of high frequency repetitive transcranial magnetic stimulation (rTMS) to the right prefrontal cortex transiently reduces cocaine craving. Drug Alcohol Depend 2007; 86:91-94.

16. Lefaucheur JP, Drouot X, Von Raison F, Ménard-Lefaucheur I, Cesaro P, Nguyen JP. Improvement of motor performance and modulation of cortical excitability by repetitive transcranial magnetic stimulation of the motor cortex in Parkinson's disease. Clin Neurophysiol 2004;115:2530-2541.

17. Elahi B, Elahi B, Chen R. Effect of transcranial magnetic stimulation on Parkinson motor function-systematic review of controlled clinical trials. Mov Disord 2009;24:357-363.

18. Tergau F, Wassermann EM, Paulus W, Ziemann U. Lack of clinical improvement in patients with Parkinson's disease after low and high frequency repetitive transcranial magnetic stimulation. Electroencephalogr Clin Neurophysiol Suppl 1999;51:281-288.

19. Borich M, Arora S, Kimberley TJ. Lasting effects of repeated rTMS application in focal hand dystonia. Restor Neurol Neurosci 2009;27:55-65.

20. De Ridder D, De Mulder G, Menovsky T, Sunaert S, Kovacs S. Electrical stimulation of auditory and somatosensory cortices for treatment of tinnitus and pain. Prog Brain Res 2007;166:377-388.

21. Tassinari CA, Cincotta M, Zaccara G, Michelucci R. Trancranial magnetic stimulation and epilepsy. Clin Neurophiol 2003;114: 777-798.

22. Santiago-Rodríguez E, Cárdenas-Morales L, Harmony T, Fernández-Bouzas A, Porras-Kattz E, Hernández A. Repetitive transcra- nial magnetic stimulation decreases the number of seizures in patients with focal neocortical epilepsy. Seizure 2008;17:677-683.

23. Takeuchi N, Tada T, Toshima M, Matsuo Y, Ikoma K. Repetitive transcranial magnetic stimulation over bilateral hemispheres enhances motor function and training effect of paretic hand in patients after stroke. J Rehabil Med 2009;41:1049-1054.

24. Lefaucheur JP, Drouot X, Ménard-Lefaucheur I, Keravel Y, Nguyen JP. Motor cortex rTMS restores defective intracortical inhibition in chronic neuropathic pain. Neurology 2006;67: $1568-1574$.

25. Lipton RB, Dodick DW, Silberstein SD, et al. Single-pulse transcranial magnetic stimulation for acute treatment of migraine with aura: randomized, double-blind, parallel-group, sham-controlled trial. Lancet Neurol 2010:70054-70055.

26. Langguth B, Tobias K, Marienhagen J, et al. Transcranial magnetic stimulation for the treatment of tinnitus: effects on cortical excitability. BMC Neurosci 2007;8:45.

27. Clarke BM, Upton AR, Kamath MV, Al-Harbi T, Castellanos CM Transcranial magnetic stimulation for migraine: clinical effects. J Headache Pain 2006;7:341-346.

28. Loo CK, McFarquahar TF, Mitchell PB. A review of the safety of repetitive transcranial magnetic stimulation as a clinical treatment for depression. Int J Neuropsyhopharmacol 2008;11:131-147.

29. Schutter DJ. Antidepressant efficacy of high-frequency transcranial magnetic stimulation over the left dorsolateral prefrontal cortex in double-blind sham-controlled designs: a meta-analysis. Psychol Med 2009;39:65-75.

30. Haut SR, Bigal ME, Lipton RB. Chronic disorders with episodic manifestations: focus on epilepsy and migraine. Lancet Neurol 2006;5:148-157.

31. Goadsby PJ, Lipton RB, Ferrari MD. Migraine-current understanding and treatment. N Engl J Med 2002;346:257-270.

32. de Vries B, Frants RR, Ferrari MD, van den Maagdenberg AM. Molecular genetics of migraine. Hum Genet 2009;126:115-132.

33. Kennard C, Gawel M, Rudolph Nde M, Rose FC. Visual evoked potentials in migraine subjects. Res Clin Stud Headache 1978;6: $73-80$.

34. Gawel M, Connolly JF, Rose FC. Migraine patients exhibit abnormalities in the visual evoked potential. Headache 1983;23:49-52.

35. Schoenen J, Timsit-Berthier M. Contingent negative variation: methods and potential interest in headache. Cephalalgia 1993;13: $28-32$.

36. MaertensdeNoordhout A, Timsit-Berthier M, Timsit M, Schoene J. Contingent negative variation in headache. Ann Neurol 1986;19: $78-80$.

37. Kropp P, Gerber WD. Is increased amplitude of contingent negative variation in migraine due to cortical hyperactivity or to reduced habituation? Cephalalgia 1993;13:37-41.

38. Schoenen J, Wang W, Albert A, Delwaide PJ. Potentiation instead of habituation characterizes visual evoked potentials in migraine patients between attacks. Eur J Neurol 1995;2:115-122.

39. Vikelis M, Mitsikostas DD. The role of glutamate and its receptors in migraine. CNS Neurol Disord Drug Targets 2007;6:251-257.

40. Sanchez-Del-Rio M, Reuter U, Moskowitz MA. New insights into migraine pathophysiology. Curr Opin Neurol 2006;19:294-298.

41. Cao Y, Welch KM, Aurora S, Vikingstad EM. Functional MRIBOLD of visually triggered headache in patients with migraine. Arch Neurol 1999;56:548-554.

42. Bohotin V, Fumal A, Vandenheede M, et al. Effects of repetitive transcranial magnetic stimulation on visual evoked potentials in migraine. Brain 2002;125:912-922.

43. Ayata C, Jin H, Kudo C, Dalkara T, Moskowitz MA. Suppression of cortical spreading depression in migraine prophylaxis. Ann Neurol 2006;59:652-661.

44. Cutrer FM, Sorensesn AG, Weisskoff RM, et al. perfusionweighted imaging defects during spontaneous migraine aura. Ann Neurol 1998;43:25-31.

45. Hadjikhani N, Sanchez Del Rio M, Wu O, et al. mechanisms of migraine aura revealed by functional MRI in human visual cortex. Proc Natl Acad Sci USA 2001;98:46887-46892.

46. Leao AAP. Spreading depression of activity in cerebral cortex. J Neurophysiol 1944:7:359-390. 
47. Bolay H, Reuter U, Dunn AK, Huang Z, Boas DA, Moskowitz MA. Intrinsic brain activity triggers trigeminal meningeal afferents in a migraine model. Nat Med 2002;8:136-142.

48. Olesen J, Burstein R, Ashina M, Tfelt-Hansen P. Origin of pain in migraine: evidence for peripheral sensitisation. Lancet Neurol 2009;8:679-690.

49. Holland PR, Schembri CT, Fredrick JP, Goadsby PJ. Transcranial magnetic stimulation for the treatment of migraine aura. Cephalalgia 2009;72:A250.

50. Keck ME, Welt T, Müller MB, et al. Repetitive transcranial magnetic stimulation increases the release of dopamine in the mesolimbic and mesostriatal system. Neuropharmacology 2002;43:101-109.

51. Strafella AP, Paus T, Barrett J, Dagher A. Repetitive transcranial magnetic stimulation of the human prefrontal cortex induces dopamine release in the caudate nucleus. J Neurosci 2001;21:RC157.

52. Michael N, Gosling M, Reutemann M, et al. Metabolic changes after repetitive transcranial magnetic stimulation (rTMS) of the left prefrontal cortex. A sham-controlled proton magnetic resonance spectroscopy (1H MRS) study of health brain. Eur J Neurosci 2003; 17:2462-2468.

53. Brighina F, Palermo A, Daniele O, Aloisio A, Fierro B. Highfrequency transcranial magnetic stimulation on motor cortex of patients affected by migraine with aura: a way to restore normal cortical excitability? Cephalalgia 2009 Apr 28; [Epub ahead of print].
54. Mohamad YM, Kothari R, Hughes G, et al. Transcranial magnetic stimulation (TMS) relieves migraine headache. Headache 2006: 46:839.

55. Mohammad TM, Hughes G, Nkrumah M, et al. Self-Administered transcranial magnetic stimulation (TMS) during the aura phase improved and aborts headache. Headache 2006:46:857.

56. Brighina F, Piazza A, Vitello G, et al. rTMS of the prefrontal cortex in the treatment of chronic migraine: a pilot study. J Neurol Sci 2004;227:67-71.

57. Teepker M, Hötzel J, Timmesfeld N, et al. Low-frequency rtms of the vertex in the prophylactic treatment of migraine. Cephalalgia 2009 Jun 8; [Epub ahead of print].

58. Roth BJ, Pascual-Leone A, Cohen LG, Hallett M. "The heating of metal electrodes during rapid-rate magnetic stimulation: a possible safety hazard." Electroenceph Clin Neurophysiol 1992;85:116123.

59. Ruohonen J, Ilmoniemi RJ. Physical principles for transcranial magnetic stimulation. In: Pascual-Leone A, Davey NJ, Rothwell J, Wassermann EM, Puri BK, eds. Handbook of Transcranial Magnetic Stimulation. New York: Oxford University Press, 2002.

60. Elwassif MM, Kong Q, Vazquez M, Bikson M. Bio-heat transfermodel of deep brain stimulation-induced temperature changes. J Neural Eng 2006;3:306-315. 